www.jmscr.igmpublication.org

Impact Factor (SJIF): 6.379

Index Copernicus Value: 79.54

ISSN (e)-2347-176x ISSN (p) 2455-0450

crossrefDOI: https://dx.doi.org/10.18535/jmscr/v6i9.123

Journal Of Medical Science And Clinical Research

IGM Publication

An Official Publication of IGM Publication

\title{
Clinical and biochemical profile of newly diagnosed type 2 diabetes mellitus patients: A Study from Rural Tertiary Care Hospital of South Karnataka
}

\author{
Authors
}

Shruthi Bettegowda ${ }^{1}$, Madhura Talkad Lakshmikumar*2

${ }^{1}$ Associate Professor, Department of Medicine, Adichunchanagiri Institute of Medical Sciences

Balagangadharanatha Nagar, Nagamangala, Mandya-571448, Karnataka, India

${ }^{2}$ Professor, Department of Medicine, Adichunchanagiri Institute of Medical Sciences,

Balagangadharanatha Nagar, Nagamangala, Mandya -571448, India

*Corresponding Author

Dr Madhura TL

Professor, Department of Medicine, Adichunchanagiri Institute of Medical Sciences, Balagangadharanatha

Nagar, Nagamangala (Tq), Mandya (District) .PIN- 571448, Karnataka (State), India

Phone+919535250064, FAX: +08234287344, Email: simplemanasu@gmail.com

\section{Abstract}

Objective: To study the clinical and biochemical profile of newly detected type 2 diabetes mellitus patients from rural areas.

Method: 100 newly diagnosed type 2 diabetes mellitus patients were included in this study. Study protocol included detailed clinical history, examination and investigations. Clinical examination and investigations were done to assess hypertension, body mass index, ischemic heart diseases, lipid profile, microvascular, and macrovascular complications of diabetes mellitus.

Results: There were 56 males and 44 females. Maximum patients were belonged to fourth decade and upperlower socioeconomic status. $18 \%$ patients had obesity and 30\% people were overweight. The prevalence of abnormal Waist to hip ratio was $46 \%$. Polyuria was the main complaint in $60 \%$ patients. $54 \%$ patients had hypertension. $40 \%$ patients had increased cholesterol, $52 \%$ patients had altered triglyceride. One or more microvascular complications were detected in $67 \%$ patients. The prevalence of neuropathy, retinopathy and nephropathy was $25 \%, 20 \%$ and $22 \%$ respectively.

Conclusion: This study showed more patients belonged to younger age group. Most of the patients were not obese but had abnormal waist to hip ratio. Hypertension was the commonest observed comorbidity. Significant proportions of our patients had microvascular complications at the time of diagnosis. Neuropathy was the commonest complication.

Keywords: Body mass index, Ischemic heart disease, Nephropathy, Neuropathy, Retinopathy, Type 2 diabetes mellitus.

\section{Introduction}

Type 2diabetes mellitus (DM) is a common non communicable disease in India. In recent years, the prevalence of diabetes in urban and rural areas has significantly increased in India $^{1}$. A recent study showed prevalence as high as $13 \%$ across rural and urban areas. Many studies proved Asian phenotype in DM. The Indian DM patient is characterized by younger age of onset, lower body mass index, higher abdominal adiposity, and 
higher cardiovascular disease risk ${ }^{2}$. These factors influence the choice of treatments that are available and selected in these patients ${ }^{3}$. Although DM is very common in south India, studies on clinical profile of newly diagnosed DM from rural south Indian areas are lacking. Therefore, the aim of this study was to explore this problem in our own setup.

\section{Materials and Methods}

Consecutive 100 newly diagnosed DM patients admitted in the medicine department of territory care hospital were considered for this descriptive observational study. Ethics committee approval was taken for the study. The written and informed consent of the patients was obtained.

Following patients were excluded from study

- Diagnosed case of diabetes patients on treatment.

- Seriously ill patients.

- Patients who refused to be a part of the study.

- Pregnancy.

- Patients on any drug therapy.

Study protocol included detailed clinical history and examination and investigations. A detailed clinical work up incorporating details of age, presenting complaints, diet, smoking, alcohol consumption, physical activity, reproductive history, socioeconomic status, body mass index and pedigree chart was made.DM was defined according to American, International and European Diabetes Association as - fasting blood sugar $($ FBS $)>126 \mathrm{mg} / \mathrm{dl}$ (fasting for at least $8 \mathrm{~h}$ ) or $2 \mathrm{~h}$ postprandial sugar $>200 \mathrm{mg} / \mathrm{dl}$ (capillary and venous) or $\mathrm{HbA} 1 \mathrm{c}>6.5 \%$ or symptoms of diabetes + random blood sugar > $200 \mathrm{mg} / \mathrm{dl}^{1}$. Height, waist and hip circumference were measured in centimetres by using a nonstretchable standard tape with a metal buckle at one end over the light clothing. Waist circumference was measured in the centre of the iliac crest and the coastal margin, and hip circumference was measured at the widest point on buttocks below the iliac crest. Weight was measured by using a digital scale. Patients were divided in to non-obese and obese on the basis of body mass index (BMI)(weight in $\mathrm{kg} / \mathrm{height}$ in $\mathrm{m} 2$ ). BMI cut off value of $25 \mathrm{~kg} / \mathrm{m} 2$ for male and $23 \mathrm{~kg} / \mathrm{m} 2$ for female was used for making diagnosis of obesity as recommended for Asian phenotype $^{4}$. Menopause was considered to be present when there was no history of menstrual periods for the last one year. Current smokers were defined as those who smoked any form of tobacco in the previous 6 months while former smoker were those who had quit more than 6 months earlier. Subjects were asked about duration of tobacco intake and amounts consumed and were divided in two groups, tobacco chewer and non-tobacco chewer. Socio- economic statuses of the patients were divided according to kuppuswamy classification ${ }^{5}$. Physical activity of patient was measured as heavy, medium and light/sedentary according to modified Minnesota leisure time questionnaire ${ }^{6}$. Systolic blood pressure ( BP) and diastolic BP were measured twice at an interval of $3 \mathrm{~min}$ in sitting position after a rest of $15 \mathrm{~min}$. Those with blood pressure > 140 / $90 \mathrm{mmHg}$ taken twice were defined as hypertensive. A diagnosis of dylipedemia was made if total Cholesterol is > $200 \mathrm{mg} / \mathrm{dl}$, Triglycerides > $150 \mathrm{mg} / \mathrm{dl}$, and LDL > 130 $\mathrm{mg} / \mathrm{dl}^{4}$. Diagnosis of neuropathy was made on the basis of clinical examination for sense of touch, pain and vibration and reflexes. $128 \mathrm{~Hz}$ tuning fork was used to examine vibration sense and $10 \mathrm{~g}$ monofilament was used to evaluate light touch perception. Fundus examination was done by Ophthalmologist for retinopathy. 24 hour urinary albumin estimation was done to diagnose diabetic nephropathy. A value of $>300 \mathrm{mg} / \mathrm{dl}$ was taken as confirmed nephropathy. Coronary artery disease (CAD) was diagnosed on the basis of electrocardiograph (ECG) changes and treadmill test. The diagnosis of stroke was based on the clinical history and examination. Peripheral arterial disease was diagnosed by history of claudication, absence of pulses or Doppler study. 
Data Analysis: Data were compiled and tabulated by using standard appropriate statistical technique, which includes numbers and percentages.

\section{Results}

In our study of 100 patients maximum incidence of DM occurred in fourth decade (Table 1). In this study 56 were males and 44 were females. The maximum number of cases was seen in upperlower socioeconomic status (SES) (30\%) (Table2). Polyuria was the main complaint in 60 patients, next in frequency was polydypsia. Ployuria and polydypsia were reported by $48 \%$ (Table 3). The major risk factors in the study group were sedentary habits (48), stress (32) family history (26), and tobacco consumption (20) (Table 4). The prevalence of abnormal Waist to hip ratio (Male $>0.95$, Female $>0.8$ ) was found to be $46 \%$ (Table 4). In our study 40 patients had increased cholesterol, 52 patients had altered triglyceride (Table 5). In present study 18 patients had obesity and 30 people were overweight (Table 6). There were 54 hypertensive patients in this study (Table 7). One or more microvascular complications were detected in $67 \%$ patients: neuropathy in 25\%, nephropathy in $22 \%$ and retinopathy in $20 \%$ patients. $20 \%$ of patients presented with one or more macrovascular complications (Table 8).

Table 1: Age incidence

\begin{tabular}{|l|c|c|}
\hline $\begin{array}{l}\text { Age groups in } \\
\text { years }\end{array}$ & $\begin{array}{c}\text { Number of DM } \\
\text { patients }\end{array}$ & Percentage \\
\hline $31-40$ & 30 & $30 \%$ \\
\hline $41-50$ & 46 & $46 \%$ \\
\hline $51-60$ & 20 & $20 \%$ \\
\hline $61-70$ & 4 & $4 \%$ \\
\hline
\end{tabular}

Table 2 Socioeconomic status

\begin{tabular}{|l|c|c|}
\hline $\begin{array}{l}\text { Socioeconomic } \\
\text { status }\end{array}$ & $\begin{array}{c}\text { Number of } \\
\text { DM cases }\end{array}$ & Percentage \\
\hline Upper & 14 & $14 \%$ \\
\hline Upper middle & 10 & $10 \%$ \\
\hline Lower middle & 20 & $20 \%$ \\
\hline Upper lower & 30 & $30 \%$ \\
\hline Lower & 26 & $26 \%$ \\
\hline
\end{tabular}

Table 3 Symptomatology

\begin{tabular}{|l|c|}
\hline Presenting Symptoms & No. Of DM cases \\
\hline Polyuria & 60 \\
\hline Polydypsia & 52 \\
\hline Weight loss & 36 \\
\hline Vomiting & 14 \\
\hline Fever & 10 \\
\hline Other & 15 \\
\hline
\end{tabular}

Table 4 DM risk factors profile

\begin{tabular}{|l|c|c|}
\hline Risk factors & $\begin{array}{c}\text { Number of } \\
\text { DM patients }\end{array}$ & Percentage \\
\hline Sedentary habits & 48 & $48 \%$ \\
\hline Stress & 32 & $32 \%$ \\
\hline Family history of DM & 26 & $26 \%$ \\
\hline Tobacco consumption & 20 & $20 \%$ \\
\hline $\begin{array}{l}\text { Abnormal waist to hip } \\
\text { ratio }\end{array}$ & 46 & $46 \%$ \\
\hline
\end{tabular}

Table 5 Dyslipidemia in DM patients

\begin{tabular}{|l|c|c|}
\hline Type of dyslipidemia & $\begin{array}{c}\text { Number of } \\
\text { DM patients }\end{array}$ & Percentage \\
\hline $\begin{array}{l}\text { Hypercholesterolemia } \\
(>200 \mathrm{mg} / \mathrm{dl})\end{array}$ & 40 & $40 \%$ \\
\hline $\begin{array}{l}\text { Hypertriglyceridemia } \\
(>150 \mathrm{mg} / \mathrm{dl})\end{array}$ & 52 & $52 \%$ \\
\hline $\begin{array}{l}\text { High density lipoprotein } \\
\text { cholesterol(<35mg/dl) }\end{array}$ & 28 & $28 \%$ \\
\hline $\begin{array}{l}\text { Low density lipoprotein } \\
\text { cholesterol(>130mg/dl) }\end{array}$ & 22 & $22 \%$ \\
\hline
\end{tabular}

Table 6: Distribution of patient according to BMI

\begin{tabular}{|l|c|c|}
\hline BMI & Number of DM patient & Percentage \\
\hline Normal & 52 & $52 \%$ \\
\hline Overweight & 30 & $30 \%$ \\
\hline Obese & 18 & $18 \%$ \\
\hline
\end{tabular}

Table 7 Hypertensive status

\begin{tabular}{|l|c|c|}
\hline Hypertensive status & Number of DM cases & Percentage \\
\hline Hypertensive & 54 & $54 \%$ \\
\hline Non hypertensive & 46 & $46 \%$ \\
\hline
\end{tabular}

Table 8 Type of Complication

\begin{tabular}{|l|c|c|}
\hline Type of complication & $\begin{array}{c}\text { Number of DM } \\
\text { cases }\end{array}$ & Percentage \\
\hline Neuropathy & 25 & $25 \%$ \\
\hline Retinopathy & 20 & $20 \%$ \\
\hline Nephropathy & 22 & $22 \%$ \\
\hline Coronary heart disease & 10 & $10 \%$ \\
\hline Peripheral artery disease & 8 & $8 \%$ \\
\hline stroke & 2 & $2 \%$ \\
\hline
\end{tabular}




\section{Discussion}

India carries a significant share of the global diabetes burden, because of recent rapid growth in economy and urbanization. Several studies demonstrated increase prevalence of DM in urban as well as rural populations.DM and its complications management causes huge burden on health care sector .Healthy life style modification is corner stone in primary prevention of $\mathrm{DM}^{3}$. Most of the studies conducted on DM are based on western population and we cannot implement the same guidelines on Indian counterparts. ${ }^{2,3,4}$ Only few studies were available on DM in rural patients from our country ${ }^{7,8}$. This study was conducted to identify clinical and biochemical profile of newly diagnosed DM patients from rural areas, in order to diagnose DM early and suggest life style modification to decrease the progression of DM. In this study maximum incidence of DM occurred in fourth decade. This finding is in accordance with other Indian studies, ${ }^{7,8,9}$ however, less than that reported by others. ${ }^{10,11}$

In this study maximum number of patients belonged to low socio economic status. The similar results were found in Mudhaliar MR et al study. ${ }^{12}$ This association may be due to more number of poor people in the area were our study was conducted. Polyuria was the main presenting complaint in this study. Similar predominance of a classic symptom in newly diagnosed diabetics has been reported in previous study. ${ }^{13}$ The prevalence of abnormal Waist to hip ratio was found to be $46 \%$ in this study. Purohit A study showed similar finding. ${ }^{14} 52 \%$ patients BMI was normal in this study, similar finding observed in Shukla V et al study. ${ }^{7}$ In this study $40 \%$ patients had increased cholesterol, 52\% patients had altered triglyceride. Previous studies showed similar findings. ${ }^{7,8} 54 \%$ of our patients were found to be hypertensive. Similar results were observed in previous studies. ${ }^{7,8}$ The most common microvascular complication was neuropathy. It was observed in $25 \%$ patients. Shukla V et al study showed $23 \%$ neuropathy. ${ }^{7}$ Bansal D et al study found neuropathy in $29.2 \%$ of patients. ${ }^{15}$
$20 \%$ of patients in this study had retinopathy. Shukla V et al study found retinopathy in $16 \%$ patients. ${ }^{7}$ Manoj Kumar et al study showed $15.36 \%$ retinopathy. ${ }^{16} 22 \%$ of patients in this had nephropathy. $16 \%$ of patients had nephropathy in Shukla V et al study. ${ }^{7}$ Manoj Kumar in his study found nephropathy in $5.56 \%$ patients. ${ }^{16}$

\section{Conclusion}

Our study showed more patients belonged to younger age group. Most of the patients were not obese but had abnormal waist to hip ratio. Hypertension was the commonest observed comorbidity. Significant proportions of our patients had microvascular complications at the time of diagnosis. Neuropathy was the commonest complication. The main limitation of our study is small sample size. More population based studies with large sample size needed in future; various geographical areas and populations should be considered.

\section{Acknowledgement: none \\ Sources of support: Nil}

\section{References}

1. Anjana RM, Deepa M, Pradeepa R, Mahanta J, Narain K, Das HK, et al. Prevalence of diabetes and prediabetes in 15 states of India: Results from the ICMRINDIAB population-based cross-sectional study. Lancet Diabetes Endocrinol. 2017; 5:585-596.

2. Ma RC, Chan JC. Type 2 diabetes in East Asians: Similarities and differences with populations in Europe and the United States. Ann N Y Acad Sci. 2013; 1281:6491.

3. Rajadhyaksha V. Managing diabetes patients in India: Is the future more bitter or less sweet? Perspectives in Clinical Research. 2018; 9(1):1-3.

4. Misra A, Chowbey P, Makkar BM, Vikram NK, Wasir JS, Chadha D, et al. Consensus statement for diagnosis of 
obesity, abdominal obesity and the metabolic syndrome for Asian Indians and recommendations for physical activity, medical and surgical management. J Assoc Physicians India. 2009;57:163-70.

5. Mishra D, Singh HP. Kuppuswamy's socioeconomic status scale- A revision. Indian J Pediatr., 2003;70:273-74.

6. Taylor HL, Jacobs DR, Shucker B,et al. A questionnaire for the assessment of leisure time physical activities. J Chronic Dis., 1978; 31:741-755.

7. Shukla V, Karoli R,Chandra A.A Study of Newly Diagnosed Type 2 Diabetes Mellitus Patients from Rural Areas. J Assoc Physicians India.2014 ; 62: 682684.

8. Vijayakumar G, Arun R, Kutty VR. High Prevalence of Type 2 Diabetes Mellitus and Other Metabolic Disorders in Rural Central Kerala. J Assoc Physicians India. 2009;57:563-567.

9. Agrawal RP, Ranka M, Beniwal R, Gothwal SR, Jain GC, Kochar DK, et al. Prevalence of micro and macro vascular complications in type 2 diabetes and their risk factors. Int $\mathrm{J}$ Diabetes Dev Ctries 2004;24:11-6.

10. Barma PD, Ranabir S, Prasad L, Singh TP. Clinical and biochemical profile of lean type 2 diabetes mellitus. Indian J Endocrinol Metab 2011;15 Suppl 1:S40-3.

11. Mukhyaprana MP, Vidyasagar S, Shashikiran J. Clinical prolife of type 2 diabetes mellitus and body mass index. Is there any correlation on? Calicut Med J. 2004;2:e3.

12. Mudhaliar MR et al. Association between socioeconomic status and diabetes in rural settings of India. International Journal of Green Pharmacy.2017;11:S144-S148.

13. Bhaskar ME et al. Presenting Features of Diabetes Mellitus. Indian J Community Med. 2010; 35(4): 523-525.
14. Purohit A, Tiwari V. Study of BMI and Waist Hip Ratio of Indians with Type2Diabetes Mellitus. International Journal of Medical Research and Review. 2014; 2(6):592-598.

15. Bansal D et al.Prevalence and risk factors of development of peripheral diabetic neuropathy in type 2 diabetes mellitus in a tertiary care setting. J Diabetes Invest. 2014; 5: 714-721.

16. Manoj Kumar et al.Chronic complications in newly diagnosed patients with type 2 diabetes mellitus in rural area of western Uttar Pradesh, India. Int J Res Med Sci. 2016 ;4(6):2292-2296. 